\title{
STRUCTURAL ANALYSIS OF FAST REFLECTOR SUPPORTING SYSTEM
}

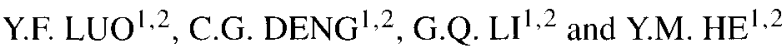 \\ ${ }^{1}$ Tongji University, ${ }^{2}$ Beijing Astronomical Observatory
}

\begin{abstract}
According to the deformation and movement requirements of the FAST reflector, a multipurpose analysis, including the load-bearing behavior, deformation, construction costs of the reflector supporting structure and its model, is presented in this paper. The advantages and disadvantages of steel and aluminum alloy structures are also discussed and compared through detailed design calculations under load-bearing capacity and normal working conditions.
\end{abstract}

Keywords: reflector supporting structure, steel, aluminum, deformation, cost

\section{Introduction}

The FAST (Qiu, 1998) (Five-hundred meter Aperture Spherical Telescope) project is now a world-wide well-known astronomical project in China. Its reflector will be a spherical surface of $500 \mathrm{~m}$ aperture and $300 \mathrm{~m}$ radius of curvature. According to the requirement of fitting a moving paraboloid of revolution, the FAST reflector must be continuously adjustable while tracking a celestial object. To this purpose, the FAST reflector is divided into approximately 1788 elementary units. Each unit is a virtual spherical hexagon of about $7.5 \mathrm{~m}$ in length on each side. It is realized by a structural unit composed of aluminum panels and a stiff supporting structure. The structure is attached to three servo controlled actuators that can drive the structure to move in the direction normal to the spherical surface. The real time movement of every elementary unit is in coordination with all adjacent units while maintaining the required paraboloid.

\section{The Aluminum Panels of the Reflector}

An elementary unit is further divided into 54 plane triangles. All apexes of a triangle are on the reflector spherical surface and the edge length of the triangle is not greater than $2.5 \mathrm{~m}$. A typical elementary unit is shown in Figure 1 .

The reflector surface is made of perforated aluminum panels. The thickness of the panel is $t \leq 1 \mathrm{~mm}$. Each hole in the panel is a $3 \mathrm{~mm}$ by $3 \mathrm{~mm}$ square hole or $\mathrm{d}=3 \mathrm{~mm}$ circular hole spaced $6 \mathrm{~mm}$ between two adjacent hole centers. The net area of the panels is almost $75 \%$ of the gross area of the reflector. The surface area of an elementary unit is $146.142 \mathrm{~m}^{2}$. The total area of the reflector surface is 


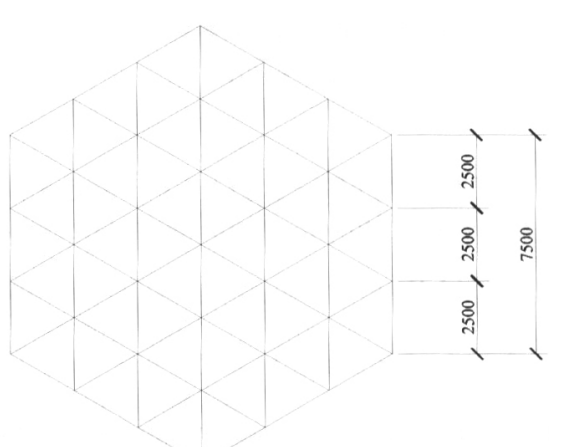

Figure I. An elementary unit.

approximately $261300 \mathrm{~m}^{2}$. The aluminum density is $2.8 \mathrm{t} / \mathrm{m}^{3}$. If the thickness of the panel is $1 \mathrm{~mm}$, the total aluminum quantity needed for the reflector panels is $558.7 \mathrm{t}$.

\section{The Supporting Structure of the Reflector}

According to the astronomical requirements for the working accuracy of the reflector (Qui, 1998), it must possess sufficient spatial stiffness, integrity and service reliability. The reflector supporting structure must ensure the surface accuracy. On the other hand, the construction costs and the service durability of the supporting structure are also major determining factors for the structure design.

There are two alternative structure supporting systems, i.e., plane structures and space structures. Most of the traditional structures, such as frames and trusses, are practically plane structures. Their out-of-plane stiffness and integrity are insufficient and their joint systems are complicated for forming space structures. Grid (or reticulated) shells are inherently space structures. The advantages of space structures over plane structures are better spatial stiffness, better integrity, lighter self-weight, easier fabrication and lower construction costs.

Two types of grid shells can be selected for the reflector structure, i.e., single layer and double layer grid shells. The strength of the first type may be sufficient for the reflector, but the spatial stiffness may not satisfy the FAST requirements. The second type has better spatial stiffness, integrity, and reliability. Although the number of joints and members is greater than that of a single layer grid shell, the self-weight will be lighter and the total construction costs will be lower. Therefore, a double layer grid shell is better and more suitable for the supporting structure of the FAST reflector.

The double layer grid shell with triangular-pyramid patterns has been finally selected for the supporting structure of the reflector. A typical grid shell is shown in Figure 2. All upper joints are on a spherical surface and all lower joints are on a 


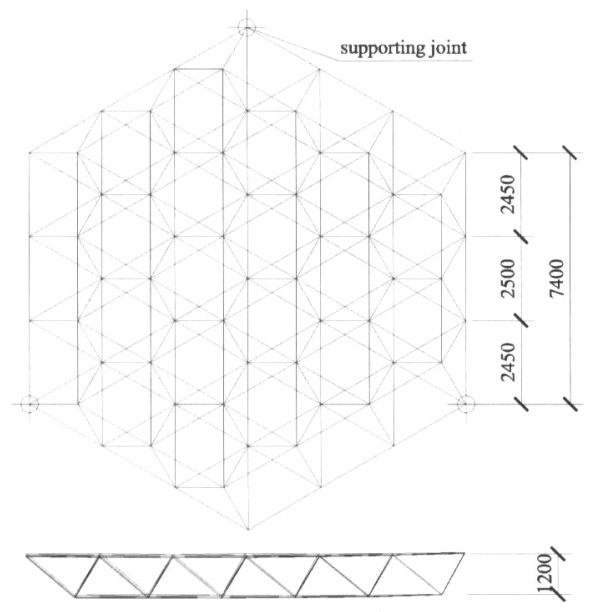

Figure 2. A typtical grid shell as a supporting structure.

concentric spherical surface. The triangle grid size of the shell is not greater than $2.5 \mathrm{~m}$. The structure height is chosen between $1.2 \mathrm{~m}$ and $1.5 \mathrm{~m}$ to achieve a balance between stiffness requirement and construction cost.

There are three supporting joints under a structural unit. They are evenly and alternatively distributed at the structure corners, shown as point markers in Figure 2. Each supporting joint is attached through mechanical devices to a servo controlled actuator which allows adjustment of the position of the corner with millimeter precision.

\section{Design and Analysis of the Supporting Structure}

The FAST project is a national key project. The construction quality and geometrical accuracy of the reflector have a direct effect on its operation. Therefore, possible structure systems are compared to yield the optimal design of the supporting structure. Two different structural materials - steel (Q235, Chinese standard steel that is equivalent to ISO630 Fe360) and aluminum alloy (AA $6061 \mathrm{~T} 6$ ) - are selected here for comparison. The advantages and disadvantages of the structures are listed and compared. Stainless steel as a weather proof structural material is not discussed in detail here because of its high construction cost.

A steel grid shell has the advantages of high spatial stiffness, integrity, low cost, small deformation and convenient manufacture, but it has the disadvantages of heavy self-weight, unbalanced thermal deformation with the aluminum reflector panels, low corrosion resistance, heavy maintenance work and high service costs.

An aluminum alloy grid shell has the advantages of light self-weight, high corrosion resistance, little maintenance work (no maintenance at all if the service environment is favorable) and identical thermal deformation with the aluminum 
TABLE I

Material consumption of the structure

\begin{tabular}{|c|c|c|c|c|c|}
\hline Materials & \multicolumn{2}{|c|}{$\begin{array}{l}\text { Consumption per unit } \\
\text { area }\left(\mathrm{kg} / \mathrm{m}^{2}\right)\end{array}$} & \multirow{2}{*}{$\begin{array}{l}\text { An elementary } \\
\text { unit consumption } \\
1.43 / 1.41\end{array}$} & \multirow{2}{*}{$\begin{array}{l}\text { Unit price } \\
\left(10^{3} \mathrm{RMB} / \mathrm{t}\right)\end{array}$} & \multirow{2}{*}{$\begin{array}{l}\text { Total cost (average for } \\
\text { all units) }\left(10^{6} \mathrm{RMB}\right) \\
16.50 \sim 17.77\end{array}$} \\
\hline Steel (Q235) & Bottom $\left(0^{\circ}\right)$ & 9.78 & & & \\
\hline & Edge $\left(60^{\circ}\right)$ & 9.65 & & & \\
\hline & Average & 9.715 & & & \\
\hline Aluminum alloy & Bottom $\left(0^{\circ}\right)$ & 4.947 & $0.723 / 0.925$ & $25 \sim 35$ & $36.83 \sim 51.56$ \\
\hline \multirow{2}{*}{ (AA6061-T6) } & Edge $\left(60^{\circ}\right)$ & 6.329 & & & \\
\hline & Average & 5.638 & & & \\
\hline
\end{tabular}

The cost of steel structure is only the initial construction cost and does not include maintenance cost. The coating of steel structure costs about $2.54\left(10^{6} \mathrm{RMB}\right)$ and may last 5 to 10 years.

TABLE II

Reactions at the supporting joints

\begin{tabular}{llllllll}
\hline \multirow{2}{*}{ Materials } & \multicolumn{3}{l}{ Tangential reaction $(\mathrm{kN})$} & & \multicolumn{3}{l}{ Normal reaction $(\mathrm{kN})$} \\
\cline { 2 - 3 } \cline { 7 - 8 } & \multicolumn{2}{l}{ Bottom $\left(0^{\circ}\right)$} & Edge $\left(60^{\circ}\right)$ & & Bottom $\left(0^{\circ}\right)$ & \multicolumn{2}{l}{ Edge $\left(60^{\circ}\right)$} \\
\hline Steel & 0 & 20.539 & & -6.535 & 10.836 & -15.127 & 11.448 \\
Aluminum alloy & 0 & 12.934 & & -3.814 & 13.563 & -14.089 & 11.811 \\
\hline
\end{tabular}

- is for compression and + is for tension.

reflector panels, but it has the disadvantages of difficult and less reliable welding and high construction costs.

Two different structural limiting states, i.e., the load-bearing capacity limit and the deformation limit, under normal working conditions, and twelve different load combinations were considered in the analysis and design of the supporting structure.

\subsection{LOAD-BEARING CAPACITY OF THE STRUCTURE}

Under the load-bearing capacity limit, the supporting structure is mainly subject to self-weight, ultimate wind load (base wind pressure $w_{0}=0.35 \mathrm{kN} / \mathrm{m}^{2}$ ), temperature change $\left( \pm 30^{\circ} \mathrm{C}\right)$ and possible snow load. The structural analysis is conducted under possible load combinations based on the factorized values of these loads, and the strength and stability of members are checked against relevant design codes (China Acadèy of Building Research, 1991; Aluminum Association, 1986). The major results are listed in Table I and Table II.

Table II shows that the reaction of steel structures is higher than that of aluminum ones. This will increase the costs of the mechanical and electrical systems. 
TABLE III

The largest displacements of the upper joints $(\mathrm{mm})$

\begin{tabular}{lll}
\hline Materials & Bottom $\left(0^{\circ}\right)$ & Edge $\left(60^{\circ}\right)$ \\
\hline Steel & 0.43 & 0.15 \\
Aluminum alloy & 0.54 & 0.20 \\
\hline
\end{tabular}

\subsection{DEFORMATION ANALYSIS UNDER NORMAL WORKING CONDITIONS}

The supporting structure must ensure the geometrical accuracy of the reflector surface under normal working conditions: the structure is subject to self-weight, working limit wind load (average wind speed $v=4.0 \mathrm{~m} / \mathrm{s}$ ), and temperature change $\left( \pm 20^{\circ} \mathrm{C}\right)$. The structural analysis is conducted under possible load combinations based on the standard values of these loads. The major results are listed in Table III.

\section{Design of the Test Model}

In order to investigate the loading behavior of the supporting structure, the functionality and the reliability of different mechanical devices, and the environmental effect on the whole reflector, a $1 / 3$ scale test model composed of four elementary units is designed. The principle of analogy is applied in the design. Twelve load combinations are also considered. Because the original grid size is rather irregular, it is adjusted for optimal design and convenient construction. Two different structural materials are also used in the test model, i.e., three different steel grid shell structures are used in three units and an aluminum alloy grid shell structure is used in one unit.

\section{Conclusions and Suggestions}

1. A double layer grid shell is better for the supporting structure of the reflector to obtain better spatial integrity, stiffness and reliability.

2. A steel structure generates larger tangential reactions on the mechanical devices than the aluminum alloy structure does. This will increase the cost of the mechanical devices and the servo-controlled actuators.

3. An aluminum alloy structure has many advantages that just meet all the requirements of the supporting structure of the reflector. Although its cost in the construction period is higher than a steel structure, its maintenance cost in operation is much lower. In general, the total costs of these two structural 
systems are well matched. In conclusion, an aluminum alloy structure would be the best choice.

\section{Acknowledgements}

This research is supported by the China Academy of Sciences and the National Natural Science Foundation of China, for which the authors are most grateful.

\section{References}

The Aluminum Association: 1986, Specifications for Aluminum Structures, The Aluminum Association, USA.

China Academy of Building Research: 1991, Regulations for Design and Construction of Space Frame (JGJ7-91) (in Chinese).

Qiu, Y.H.: 1998, The Novel Design for a Giant Arecibo-type Spherical Radio Telescope with an Active Main Reflector, MNAS 301, 827-830. 